\title{
Quando o projeto era moda: projetos sociais, juventudes e a política de "pacificação" no Rio de Janeiro.
}

\author{
Fátima Cecchetto; \\ Juliana Corrêa; \\ Patrícia Farias
}

\section{Introdução}

"Agora para mim é assim, um lugar que está dando oportunidade às pessoas de crescer, de viver, de trabalhar, e a gente não tinha muito isso não. Porque o que estava na moda era o tráfico, então todo mundo vestia essa camisa. Agora como a moda é outra, todo mundo procura melhorar. Todo mundo está reconhecendo que estão chegando as coisas boas, todo mundo tá olhando para si próprio, $e$ (pensando) "tô mudando". Entendeu? (...) Porque o que você tinha era convite [para entrar no tráfico]. Hoje eu chamo o pessoal para fazer um curso, mas antes não tinha o curso."

Esse trecho é de uma entrevista realizada em 2012, com um jovem de 22 anos, branco, no contexto da chamada "política de pacificação do Rio de Janeiro", proposta que envolvia investimentos estatais em medidas de segurança pública através da implantação de postos de policiamento permanente em favelas. Auto-intitulado "ex-segurança do tráfico", nosso interlocutor havia conseguido, com ajuda de um familiar, participar de um curso profissionalizante, promovido por uma ONG no Complexo do Alemãoํ.

\footnotetext{
${ }^{1}$ A partir da década de 1980, o Complexo do Alemão, assim como as demais favelas cariocas, passou por um processo de intensificação da violência criminal, caracterizado pela diversificação do "crime-negócio", com destaque para o mercado de venda de drogas e de armamentos cada vez mais letais (Corrêa, 2013). Apontada como um 
A favela, situada na zona norte da cidade, foi ocupada militarmente em 2010, como prenúncio da instalação das Unidades de Polícia Pacificadora, as UPPs.

Característica marcante deste jovem era falar abertamente sobre sua passagem pela "vida do crime" na presença dos pesquisadores, destacando os riscos e prazeres de sua experiência no negócio ilegal de drogas. Porém, o medo de ser preso ou morrer no novo cenário de "pacificação" - termo fundado paradoxalmente na lógica da "guerra" o motivou a procurar uma atividade socialmente aceita, como a de monitor de projeto, uma espécie de mediador comunitário entre as ONGs de fora e as de dentro das favelas.

Naquele momento havia uma percepção de que mais iniciativas estavam chegando ao local. Alguns jovens deixavam transparecer nas conversas o sentimento de que os projetos sociais "estavam na moda". A expressão aglutina duas características da perspectiva juvenil num contexto de intervenções políticas e sociais. A primeira, a de que participar de um projeto era um procedimento comum a um grande número de jovens - era "a coisa a fazer".

Neste sentido, embora, como lembra Bourdieu (1983), a "juventude seja apenas uma palavra", cuja configuração, para além da idade, será condicionada por posições de classe (entre outras pertenças)", sugerimos que é inegável a relevância dos valores e práticas dos pares para o comportamento individual - ou seja, no contexto juvenil, "moda" é algo a ser levado a sério, pois expressa a prática de um grupo que partilha a mesma faixa etária, tendendo portanto a ser seguida por cada jovem (sobre a vinculação entre juventude e pobreza em diferentes contextos, cf. também Dubet, 1987; e Arce, 1999; sobre a conexão entre moda, provisoriedade e sua importância na contemporaneidade, cf. Lipovetsky, 2009).

esconderijo para os chefes de uma das maiores facções criminosas, a favela passou a ser descrita como um dos mais violentos lugares da cidade pela expressiva quantidade de armamentos e drogas, além, é claro, de homens dispostos a atuar no circuito dessa atividade controlando e dominando o território.

RRASILIANA- Journal for Brazilian Studies. Vol. 4, n.2 (2016). ISSN 2245-4373. 
Todavia, como também o próprio termo indica, há uma segunda percepção, que advém da noção da provisoriedade dessas iniciativas. Afinal, toda moda é passageira.

O propósito deste artigo é apresentar algumas reflexões sobre as percepções de jovens de camadas populares sobre suas expectativas de futuro, num contexto de investimento estatal em políticas de segurança pública, e o papel dos chamados "projetos sociais" neste contexto. A associação entre juventude e vulnerabilidades e as suas possíveis implicações no reforço de estereótipos negativos sobre os jovens pobres, foco das intervenções, também será objeto de discussão. Assim, o texto tem o intuito de ampliar o debate sobre as iniciativas institucionais dirigidas aos segmentos juvenis, e as representações sobre elas, trazendo à tona um pouco das situações encontradas em nossos trabalhos de campo em favelas.

O texto tem ainda o objetivo de contribuir para a análise sobre uma modalidade de atuação policial nas favelas cariocas inicialmente pensada como uma política para retomada estatal de territórios dominados por grupos armados, que apesar de uma arrancada promissora, não conseguiu promover a transformação que apregoava, mas que chamou a atenção de modo considerável para alguns problemas de segurança pública de extrema importância que atingem os grupos considerados mais vulneráveis.

Sem dúvida, esses objetivos não podem ser explorados com profundidade nos limites deste artigo. É possível, entretanto, expor algumas linhas de pensamento baseadas nas pesquisas desenvolvidas com jovens, moradores ou não de favelas, desde 1994, abordando os temas da violência, das sociabilidades e da construção social da masculinidade. Desse modo, o presente texto dá continuidade à síntese teórica e metodológica que ancorou trabalhos anteriores e segue alicerçando as investigações em andamento nestes locais. Ele também traz à tona as inquietações que apareceram ao 
longo desses anos de acompanhamento da política de segurança e da atuação da polícia com os jovens nas favelas cariocas.

\section{O passado recente: Alemão, 2012.}

No início de 2012, a sensação que vários moradores, particularmente os mais jovens, experimentavam, era de que o Complexo do Alemão também estava na moda; havia o incremento de algumas atividades comerciais e turísticas no local, ao mesmo tempo em que era exibida uma telenovela que se passava na favela exaltando personagens e modos de vida tidos como típicos da localidade. A visita de um monarca europeu ecoou como outro indício da prosperidade do Complexo mundo afora. Naquele momento, era comum a comparação em termos de recursos existentes na favela e escassos em outras, reverberando novamente a questão da hierarquia simbólica presente entre espaços da cidade do Rio de Janeiro, expressa de forma tradicional através dos pólos Zona SulBarra e Zona Norte-subúrbios (para maior discussão a respeito, cf. Farias, 2003). Essa hierarquia se desdobra numa hierarquia entre favelas da Zona Sul (melhor posicionadas) e "as outras" (Cecchetto e Farias, 2009). O Complexo do Alemão, através da visibilidade na grande imprensa, parecia então desafiar essa configuração e calcar postos mais altos nessa linha hierárquica.

Em termos mais amplos, naquele momento, especulava-se sobre uma nova inserção da cidade no cenário internacional, decorrente, dentre outros fatores, de sua indicação como sede de grandes eventos esportivos, como a Copa do Mundo de Futebol de 2014 e as Olimpíadas de 2016. Como consequência dessa especulação, os impactos econômicos, políticos e sociais já se faziam perceber no cotidiano dos habitantes. Foi 
nesse contexto que uma política de segurança ganhou espaço no debate público, sendo apresentada através do projeto das Unidades de Polícia Pacificadora - UPP.

As UPP integram um programa da Secretaria Estadual de Segurança Pública do Estado do Rio de Janeiro com o objetivo de "instituir polícias comunitárias em favelas como meio de retomar territórios ocupados por grupos criminosos nessas localidades e pacificar as áreas"2. Para tanto, as UPP vieram com a promessa de oferecer um "novo" serviço policial, baseado no policiamento comunitário ou, como vem sendo chamado, policiamento de proximidade, o que demandou um investimento na forma como os agentes foram apresentados. Com vistas a dar mais credibilidade à Polícia Militar e ao projeto, foram contratados profissionais recém-ingressados na corporação para atuar nas unidades, ou seja, policiais que não teriam participado de episódios de incursões violentas em áreas de favela. O mote seria promover a "mudança de uma polícia de combate e confronto para uma polícia de prestação de serviço em segurança pública", conforme anunciado no próprio site institucional do governo do Estado ${ }^{3}$.

Uma das metas das UPP, iniciada em 2008 na favela Santa Marta (Zona Sul da cidade), seria retomar para o Estado, a curto prazo, os territórios alegadamente dominados pelo "tráfico" e, assim, modificar os alarmantes índices de violência nesses locais. Em longo prazo, o projeto ambicionava integrar simbólica e socialmente as favelas "pacificadas" ao conjunto da cidade "formal", ampliando as condições de possibilidade de expansão da cidadania aos moradores através da maior oferta de bens e serviços públicos.

Dito isso, para que essa política de segurança fosse viável tanto do ponto de vista interno (da corporação), quanto do externo, ou seja, da sociedade carioca, as UPP

\footnotetext{
${ }^{2}$ Cf. site www.upp.rio.gov.rj

${ }^{3}$ http://www.rj.gov.br/web/informacaopublica/exibeconteudo?article-id=1041262. Acesso em: 15/07/2015
}

$3^{\text {RASILIANA- Journal for Brazilian Studies. Vol. 4, n.2 (2016). ISSN 2245-4373. }}$ 
contaram, desde o início, com um amplo apoio midiático e maiores recursos orçamentários que as propostas de policiamento comunitário precedentes, o que pode ter contribuído para o maior alcance de suas proposições. Soma-se a isso o contexto econômico e político favorável à sua implantação, caracterizado, como dito anteriormente, pela nomeação da cidade como sede de megaeventos esportivos, o que demandou do governo o desafio de propor medidas para a redução da violência, bem como induziu o interesse do setor privado (de agentes empresariais), seja para a valorização de áreas de interesse econômico do mercado imobiliário, seja para a formalização do mercado das favelas.

Não foi à toa que logo no início de sua implantação, em 2010, o projeto recebeu grande aporte de recursos de importantes grupos empresariais. Destaca-se nesse cenário a empresa OGX, cujo proprietário Eike Batista assegurava o investimento de $\mathrm{R} \$ 20$ milhões por ano em infraestrutura e logística (construção de sedes, compra e doação de equipamentos e formação de policiais especialmente para atuação nas UPP). Esse investimento, porém, foi cancelado em 2013, diante da crise financeira do grupo empresarial ${ }^{4}$.

No início da implementação das unidades, o trabalho policial passou a ser ele mesmo alvo de maior controle e vigilância pela população. Tanto que, nas palavras de um jovem morador de favela por nós entrevistado, naquele contexto, os casos de violação policial teriam mais visibilidade na grande imprensa; em suas palavras: "se acontecer alguma coisa aqui hoje, amanhã a mídia já está aqui".

Entretanto, apesar da propaganda midiática em torno das UPP e de sua centralidade no debate público, pouco foi feito no sentido de consolidação de uma

\footnotetext{
${ }^{4}$ Cf.http://odia.ig.com.br/noticia/rio-de-janeiro/2013-08-10/eike-batista-cancela-r-20-milhoes-que-injetava-por-anonas-upps.html. Acesso em 10/8/2015.
} 
política pública de Estado. Sendo assim, a estrutura normativa que dá embasamento às UPP ainda hoje é considerada incipiente, ao ponto de vários estudiosos já terem sinalizado que não existe um conjunto de ações que possa ser generalizado para várias localidades, mas sim, uma "filosofia" (Cano, Borges e Ribeiro 2012) que inspira o projeto e que se desenvolve de maneira distinta em cada contexto de acordo com o comando da unidade e suas coalizões com os poderes decisórios.

Possivelmente, o baixo grau de normatização, aliado à falta de avaliação das atividades, contribuíram para um desgaste da proposta, tendo em vista que dependia muito mais do esforço empreendido pelos profissionais de ponta do serviço policial, principalmente o dos praças encarregados do controle cotidiano da ordem nas áreas ocupadas (Machado da Silva, 2010).

Pode ser dito que desde a instalação das UPP não houve uma alteração substantiva nesse quadro e que, segundo os entrevistados, determinadas práticas policiais consideradas inadequadas continuam, tais como: revistas abusivas constantes, proibição de práticas de lazer e sociabilidade locais, a adoção de toques de recolher em determinadas áreas, entre outras atividades que ultrapassam as funções policiais propriamente ditas (Corrêa, 2013; Machado da Silva, 2010). Nas favelas cariocas "pacificadas", persistem na memória coletiva dos favelados a violação dos direitos, os corpos feridos e mortos e a contínua corrupção dos policiais. Tais fatos e situações alimentaram e alimentam ressentimentos e desconfianças mútuas, marcando negativamente as interações entre moradores e policiais.

Uma outra visão sobre os dilemas enfrentados pela "política de pacificação" diz respeito à ampliação do mandato policial. Pesquisa desenvolvida por Muniz e Mello (2015) com comandantes da Polícia Militar mostrou o quanto as diversas atribuições dadas à polícia de proximidade colaboraram para uma concepção de mandato policial 
tão estendido que tornou-se mais um problema que uma solução, já que foi designado à polícia encampar funções de outras agências públicas encarregadas de políticas sociais e infraestrutura urbana (p.54). Portanto, os significados da "pacificação" nas narrativas dos moradores das favelas cariocas precisam ser analisados à luz dos sentidos dados às relações com a polícia muito antes do novo paradigma de policiamento ter surgido, o que precisa ser melhor investigado.

\section{As UPP e o caso Amarildo: 2013 e tudo muda}

O caso Amarildo - pedreiro desaparecido após ser preso em uma sede da UPP na favela da Rocinha, uma das maiores favelas do Rio de Janeiro - ao evidenciar o recurso às práticas ilegais e violentas utilizado pela polícia, deu visibilidade aos inúmeros casos de desaparecimentos não esclarecidos pela polícia e operou um recuo do entusiasmo acrítico em torno das UPP. A demora das autoridades da segurança pública em admitirem o envolvimento dos policiais foi mais um fator que reforçou discursos reativos que clamavam pelo fim das UPP.

Nesse contexto, ocorreu uma intensa mobilização social para que o desaparecimento fosse investigado e os culpados punidos. Prova disso foi a veiculação do slogan "Cadê o Amarildo?" nas redes sociais e nas passeatas de junho de 2013, reunindo vários grupos e partidos políticos em torno da redução da tarifa do transporte público.

Esse caso representou um marco temporal nas visões sobre as UPP, que passaram a ser alvos de ataques quanto a sua efetividade como política de enfrentamento da criminalidade violenta. A esse quadro seguiu-se um retorno dos confrontos entre 
bandos armados e a polícia em determinadas favelas, com tiroteios frequentes e mortes de moradores, supostos traficantes e policiais.

A despeito disso, estudos avaliativos iniciais sobre as UPP (Cano, Borges e Ribeiro, 2012) demonstraram que houve uma diminuição dos homicídios nas áreas ocupadas. Contudo, há controvérsias em relação a esses dados, pois o número de pessoas desaparecidas aumentou na cidade e no Estado do Rio de Janeiro, gerando questionamentos sobre um possível mascaramento de casos de homicídios, o que ainda precisa ser melhor estudado.

Enfim, como resultado de todo esse processo, temos, em 2014, 38 UPP instaladas, segundo dados da Coordenadoria de Polícia Pacificadora (CPP) da Polícia Militar do Estado do Rio de Janeiro. Elas cobrem aproximadamente 264 territórios, e uma população estimada de mais de 1,5 milhão de pessoas, empregando aproximadamente 9.543 policiais, cuja remuneração, em 2012 , era de $2.169,33$ reais $^{5}$. No foco de nosso estudo, o Complexo do Alemão, foram instaladas quatro unidades de polícia

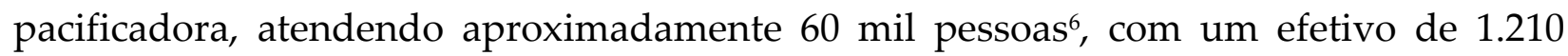
policiais militares.

Para além das UPP, no entanto, expandiu-se neste cenário "pacificado" do Alemão uma outra configuração importante: a das organizações não-governamentais com ações voltadas para o universo juvenil, os "projetos sociais". É o que veremos a seguir.

\footnotetext{
${ }^{5}$ Disponível em: < http://www.rj.gov.br/web/imprensa/exibeconteudo?article-id=767744>. Acesso em 20/07/2015.

6 Disponível em: <http://www.riomaissocial.org/territorios/complexo-do-alemao/?secao=inicio $>$. Acesso em 20/07/2015.
} 


\section{Projetos sociais e empreendedorismo juvenil}

Como já discutido por Novaes (2006), os projetos sociais constituem o resultado de uma série de iniciativas de Organizações Não-Governamentais (ONGs) e empresas que marcaram a década de 1990 no Brasil, num contexto de escassez de políticas públicas (para uma análise do contexto de surgimento destas organizações no Brasil, cf. Landim, 1998).

As ONGs no Brasil vêm sofrendo um processo de expansão acelerado. Em pesquisa de 2010, promovido pelos Instituto Brasileiro de Geografia e Estatística (IBGE), Instituto de Política Econômica Aplicada (IPEA) e Associação Brasileira de ONGs (ABONG), havia pouco mais de 290 mil Fundações Privadas e Associações sem Fins Lucrativos (FASFIL) no país, das quais 44,2\% atuavam na região sudeste. Destas, 18,6\% tinham atuação em áreas de políticas públicas. Não há dados precisos quanto ao número e formas de atuação de ONGs na área aqui estudada, o Alemão; no entanto, numa listagem publicada na página eletrônica de uma organização chamada Ongs Brasil, dados aproximados indicam a presença de 36 organizações nos bairros vizinhos ao Complexo ${ }^{7}$.

As atividades promovidas pelos projetos variam bastante, assim como o públicoalvo. Em geral, os projetos são de curta duração (menos de um ano) e voltados para jovens de baixa renda. Os conteúdos giram em torno de atividades profissionalizantes, por exemplo, inglês e informática, incluindo práticas esportivas. Outros focalizam ações relacionadas ao tema da cidadania e da cultura. Todos, porém, acionam a gramática da

\footnotetext{
${ }^{7}$ Este número diz respeito a ONGs existentes na Penha, Penha Circular, Inhaúma, Olaria, Bonsucesso e Ramos. Cf. http://www.ongsbrasil.com.br. Acesso em 10/8/2015.
} 
escassez de oportunidades de trabalho e renda para a juventude pobre, descrita como mais vulnerável à violência, seja como vítimas ou autores.

Contudo, há uma forte seletividade para o ingresso nos projetos. Pode ser dito que a trajetória da pessoa e as relações que mantém com outros indivíduos desta rede podem facilitar a sua entrada nela. Na maioria das situações por nós observadas ao longo da pesquisa, a entrada nesse campo exige do indivíduo o desenvolvimento de um conjunto de disposições, ou seja, de um determinado habitus (Bourdieu e Wacquant, 2005). Nesse aspecto, Novaes (2006) chama atenção para a figura do "jovem de projeto", isto é, indivíduos que acabam por se apropriar da linguagem do campo específico dos programas sociais incluindo-a em suas estratégias de "sobrevivência social".

Assim, há um aprendizado de palavras, gestos, atitudes e práticas que gradativamente vão sendo incorporados pelos sujeitos. Esse habitus, por sua vez, dialoga com outros existentes no local, principalmente com aquele dos denominados "envolvidos", categoria nativa utilizada tanto por gestores e moradores quanto por policiais, para classificar de forma genérica os jovens que transitam pelo crime-negócio das drogas e armas nas favelas (Zaluar, 2004; Misse, 2011a).

O termo "envolvido" carrega duas proposições: a ideia de que existe proximidade com o "tráfico", adquirindo ao mesmo tempo o sentido de um atributo moral negativo aplicado indistintamente aos moradores de favelas. Por esse motivo, o candidato ideal de projeto não deve estar "envolvido" com ações criminalizáveis, mas ao mesmo tempo, significativamente, é desejável que seja considerado em situação de vulnerabilidade para justificar as políticas sociais construídas nessa chave de oferecer alternativas para que não sejam "atraídos" para a criminalidade. 
Esse aspecto de "criar caminhos" para os jovens das classes sociais mais baixas que "não estudam e nem trabalham" - os jovens "nem nem" (Ver Cardoso, 2013), marca a maioria das iniciativas e programas sociais, dos quais nem todos os jovens pobres se beneficiam (Monteiro, 2009). Assim, para garantir um lugar ao sol para alguns, a vigilância moral é uma das estratégias adotadas pela maior parte dos coordenadores dessas iniciativas. Eles tentam exercer o controle (com mais ou menos repressão) sobre determinadas práticas ligadas ao lado "errado" da vida, incentivando o afastamento das "más companhias".

Embora não seja possível aprofundar aqui a discussão da vulnerabilidade, cabe chamar atenção para alguns aspectos. Quando se fala sobre as alternativas para o enfrentamento da chamada criminalidade juvenil, a noção de vulnerabilidade emerge, salientando sua centralidade na fundamentação de políticas sociais. Há o reconhecimento de que uma intervenção poderá atuar como recurso profilático na redução da morbimortalidade da população masculina jovem, mais exposta aos circuitos da violência letal (Waiselfisz, 2015).

Por esse motivo o uso do termo vulnerabilidade mostra-se mais adequado que risco, por inferir o impacto das desigualdades sociais como fator que atinge determinados grupos mais que outros. Porém, ainda que o paradigma coletivo inerente à ideia de desigualdade social esteja presente no dispositivo da vulnerabilidade, as mudanças são sempre imaginadas em termos individuais. É nesta dupla chave, entre o coletivismo e o individualismo, que os projetos operacionalizam suas intervenções.

A noção de vulnerabilidade repercute nas imagens que a sociedade constrói sobre os jovens pobres. O que tem gerado uma série de indagações sobre as implicações dessa visão, principalmente porque este tipo de discurso muitas vezes acaba por reforçar os 
estereótipos predominantemente negativos através dos quais a juventude pobre é representada: como um problema social (Ver Pais, 1990).

Os homens têm proeminência nas intervenções institucionais, sem que, no entanto, as relações de gênero sejam de fato problematizadas. Não basta apenas mencionar o impacto das estruturas mais amplas que modelam as práticas consideradas “desviantes". É preciso também voltar a atenção para os aspectos da socialização de gênero dos meninos e homens nos contextos atingidos pela pobreza e violência. Portanto, neste processo, é preciso também considerar como as identidades masculinas têm sido construídas em suas versões mais ou menos rígidas ou hegemônicas.

Conforme nos indicaram os depoimentos dos rapazes entrevistados, ser homem, morador de favela, jovem e negro aumenta, consideravelmente, suas chances de se tornarem alvos das acusações de "comportamentos delinquentes" pelos professores e de sofrerem perseguições dos policiais como "bandidos", ampliando a sujeição criminal. Em alguns casos, a rotulação como criminosos pode torná-los mais dispostos a agir com violência, reforçando os estereótipos de classe, idade, território, cor e principalmente de uma versão de masculinidade violenta e guerreira.

A naturalização do papel de homem como provedor e na posição de mando também intensifica o apelo para sua participação mais expressiva na dinâmica do negócio do crime. No entanto, como estudos pioneiros já demonstraram, a questão da participação de jovens no "mundo do crime" não pode ser discutida sem que se reconheça a dinâmica do comércio ilegal de drogas organizado transnacionalmente e a estrutura de poder subjacente a esta atividade que invadiu a vida dos moradores das comunidades pobres em várias cidades do Brasil, afetando principalmente os homens jovens (Zaluar, 2014). A análise precisa levar em conta a organização do crime em redes, compostas também por mulheres, além de crianças e idosos. Os homens jovens que 
enveredam pelas carreiras "criminosas" constituem uma pequena parte dos moradores de áreas pobres e de favelas, não sendo possível generalizar esse ethos para o conjunto dos habitantes do sexo masculino. Porém, a autopercepção da exposição a situações de vulnerabilidade, incluindo uma maior chance de morrer assassinado, é marcante entre eles, como veremos a seguir.

Aqui, nos deteremos na análise das narrativas de jovens que integraram um projeto social promovido por uma ONG no Complexo do Alemão, em momentos recentes, porém bastante distintos do cenário atual, como já frisado. Como mencionado anteriormente, lançamos mão de uma rede de contatos estabelecida em pesquisas anteriores, (desde 1994), para realização do trabalho de campo etnográfico entre os anos de 2010 e 2012. O contato prolongado no campo permitiu estreitar vínculos com o circuito jovem da localidade, auxiliando posteriormente no estabelecimento de laços de confiança para a realização dos grupos focais.

Em 2011, organizamos, junto com um jovem morador do Complexo entrevistas em grupo com rapazes e moças entre 18 e 25 anos que participavam de um curso profissionalizante, promovido por uma ONG internacional em parceria com instituições locais. Os encontros contaram com um roteiro de entrevistas elaborado previamente de forma semi-estruturada. No primeiro eixo os jovens foram encorajados a falar sobre suas vidas, com questões relacionadas à idade, local de moradia, estudo e trabalho. No segundo eixo o objetivo era conhecer o perfil familiar, o foco então foi sobre a profissão dos pais e o relacionamento com os familiares. No terceiro eixo as perguntas tinham relação com o lazer e a sociabilidade. Nessa parte da entrevista os jovens se sentiam mais à vontade para falar, o que facilitou no desenvolvimento da etapa seguinte na qual foram abordadas questões relacionadas ao chamado processo de "pacificação" e a 
interação com os policiais. Por fim, foram abordadas questões sobre o curso e suas expectativas e projetos de futuro.

Esta iniciativa integrava um programa voltado para jovens de baixa renda, desenvolvido em 30 países. O segmento focalizado conforme informações divulgadas no site institucional era aquele entre 15 a 25 anos, "desconectado da educação formal e fora do mercado de trabalho".

A proposta era a quebra do ciclo de pobreza através do compromisso com trabalho, educação, família e comunidade, por meio da liderança comunitária e do chamado empreendedorismo (Almeida, 2008). Desse modo, a tônica era criar meios de vida sustentáveis, viáveis para todos os jovens, através da formação, da educação, do emprego e do auto-emprego (auto-agenciamento), que expandissem suas conexões na localidade e fora dela. Nessa linha, havia a ênfase na mobilização do grupo para viabilização de serviços de infraestrutura comunitária que precisavam ser construídos ou reconstruídos tais como habitação, escolas, postos de saúde e infraestrutura verde.

Pode ser dito que, em termos de proposta pedagógica, o objetivo era tanto formar mãode-obra qualificada, quanto fortalecer laços comunitários. $\mathrm{O}$ auxílio financeiro aliado à promessa de encaminhamento para o mercado de trabalho atraiu os jovens de ambos os sexos em busca de oportunidades de ascensão social.

Conforme foi possível observar ao longo de dois anos de pesquisa, era frequente a visita e o acompanhamento de apoiadores do projeto, fossem eles representantes da ONG responsável por desenvolver a metodologia internacional no Rio de Janeiro, fossem das ONGs parceiras, e até mesmo a visita de estrangeiros coordenadores do projeto internacional.

A presença dessas instituições em seus locais de moradia era novidade para os jovens. Ainda mais pelo fato de terem sido convidados a falar sobre suas vivências e 
expectativas de futuro. Isso contribuiu para que refletissem mais sobre suas trajetórias, gerando uma maior auto-confiança para sonhar com uma carreira mais prestigiosa. Um dos produtos foi a reforma de uma residência para um morador portador de necessidades especiais, reforçando a vertente do fortalecimento dos laços grupais. Além disso, numa segunda etapa os jovens puderam trabalhar em pequenos grupos para realizar reformas em suas próprias casas, e no espaço da ONG local, com o auxílio de materiais de infraestrutura ofertados por outras ONGs parceiras.

Nos três encontros realizados, reunindo em torno de 10 jovens em cada um, chamou atenção que a maioria não estava estudando naquele momento. Alguns haviam parado os estudos antes mesmo de concluir o Ensino Fundamental. Dentre os poucos que haviam ingressado no Ensino Médio, uma parcela menor ainda concluiu esta etapa. Em geral, falar sobre esse assunto gerava certo constrangimento, uma vez que eles se apressavam em encerrar a conversa afirmando que pretendiam retomar os estudos no ano seguinte, na modalidade de um supletivo. Cabe dizer que houve uma diferenciação entre os gêneros nessa questão. Os homens alegam que tiveram que parar de estudar para procurar emprego. Dois rapazes relataram que interromperam seus estudos no ensino fundamental ao passarem a praticar atividades ilícitas, como assaltos e roubos. Segundo eles este foi um momento crucial para seu afastamento de alguns circuitos, principalmente a escola. Já as moças atribuíram a interrupção ao fato de terem engravidado e terem vergonha de ir à escola "quando a barriga começou a crescer".

Outros motivos alegados foram mudanças de residência (que demandavam a transferência de escola), que acabavam resultando na perda do ano letivo. Desse modo, o retorno para o ambiente escolar no ano seguinte era confrontado com as dificuldades de adaptação ou ainda com o trabalho, questões sempre levantadas como empecilhos, mesmo entre aqueles que não estavam trabalhando. De fato, não são poucos os que 
optam ou são forçados a deixar a escola em troca de trabalho, principalmente para suprir demandas familiares. Geralmente isso acontece no período de férias, nos quais eles começam a realizar "bicos" e acabam por não voltar à escola. No entanto, para além desse aspecto da aquisição de renda, foi possível observar que mesmo entre os jovens que tinham mais recursos familiares, a interrupção do ciclo escolar esteve presente.

Nesse sentido, os dados corroboram os estudos já realizados que atribuem a evasão escolar a uma questão cultural que envolve não só a necessidade imediata de renda, mas também uma descrença das famílias pobres na educação escolar formal, dada a constatação da existência de muitas barreiras para a ascensão social dos filhos (Cardoso, 2013).

Com relação à inserção no mercado formal, esta é considerada a parte mais difícil, devido à baixa escolaridade e à pouca oferta de empregos. De fato, as tendências dominantes em muitos países desenvolvidos e em desenvolvimento sugerem que o desemprego é um problema crônico e crescente particularmente para os jovens trabalhadores com menor grau de escolaridade (Barker, 1998).

No grupo, um rapaz, respondendo à pergunta sobre o que imaginava para si no espaço de dez anos, afirmou que não pensava em nada, pois em dez anos ele não sabia se estaria vivo. Essa fala pode ser compreendida como uma forma juvenil jocosa de falar sobre as incertezas que os rodeiam nessa etapa da vida.

Não foram poucos os depoimentos nos quais os jovens referiam-se ironicamente a si mesmos como indivíduos que "contrariam as estatísticas" pelo simples fato de estarem vivos num contexto em que ser morador de favela representa um maior risco de serem alvo de morte violenta. É marcante essa autopercepção da sua maior exposição a situações de vulnerabilidade face ao estigma que carregam por sua condição de classe, cor e, principalmente, local de moradia. 
É importante prestar atenção às variações nos discursos e formas de lidar com esse cenário para compreender, através desses relatos, como os indivíduos idealizam projetos de vida apesar dos contextos e conjunturas desfavoráveis que os rodeiam. A maioria dos relatos impressiona pelo grau de agenciamento de alguns para lidar com problemas e lutar para "fazer o certo" para si e para as famílias. Nisto se insere o desejo de realizar cursos técnicos e fazer faculdade por alguns dos entrevistados de ambos os sexos nos grupos focais.

“Ah, o que está dando para ser, e é o que eu estou sendo, monitor, eu tô lutando para conseguir algo melhor para mim, mas está muito difícil entendeu? Ter que estudar, terminar meus cursos."

“Eu quero fazer o curso de Técnico de Segurança do Trabalho e fazer faculdade de engenharia."

“Eu quero me formar em administração, já fiz curso técnico, fiz curso de economia e trabalho na área de administração, de carteira assinada."

As narrativas acima ilustram os sonhos acalentados quanto a uma melhor formação profissional para o mercado de trabalho. Como muitos rapazes haviam trabalhado de modo informal e precário - no ramo da construção civil, no transporte alternativo e no comércio local - a busca por um serviço de "carteira assinada" era uma demanda entre eles.

Naquele momento o curso foi veiculado como uma oportunidade nesta direção de oferecer uma melhor qualificação, ao mesmo tempo em que se apresentava como 
uma opção, inclusive para os que tinham passagem pelo sistema prisional e não conseguiam emprego, conforme ilustra depoimento abaixo:

“Tipo assim, eu tava procurando serviço, mas não tava conseguindo em lugar nenhum. Todo mundo estava fechando a porta. Não falavam que é porque eu tinha passagem [na polícia], mas eu tinha certeza porque eles estavam precisando, eu fui indicado para trabalhar na empresa e cheguei lá e eles puxaram o meu documento aí viram e não me aceitaram. E aqui vai ser uma boa porque daqui eles já vão encaminhar para a empresa. Tipo, já vai sair daqui com emprego, carteira assinada. E, tipo assim, eu quero continuar os meus estudos, não quero mudar de vida nunca mais, quero continuar estudando, quero começar a trabalhar na construção civil e quero ser um engenheiro."

Como o depoimento deixa entrever, ter algum tipo de renda segue sendo uma questão central na definição das identidades masculinas. Há uma pressão direta para que os homens jovens tornem-se produtivos, porém as chances de refletir a respeito de seu futuro imediato sem se influenciar pela obrigação de ser o provedor são poucas.

Reunir jovens em um determinado dia e horário para conversar com pesquisadores sobre suas expectativas com relação ao futuro já é um desafio, mais ainda quando se trata de abordar suas percepções com relação a um outro assunto, mais delicado: as mudanças no cotidiano a partir da chegada das UPP na favela. Assim, era esperado que eles se calassem e não estivessem dispostos a falar sobre o tema da polícia, considerado muito perigoso até para os pesquisadores. No entanto, contrariando as nossas ideias, os jovens se mostraram abertos para conversar e emitiram suas opiniões 
com relativo grau de franqueza. Ouvimos muitas histórias que tratavam sobre a presença da polícia na favela a partir de perspectivas variadas.

Pode ser dito que a "chegada da UPP" foi entendida enquanto um marco temporal pelos moradores, representando inicialmente um novo cenário, marcado pela vinda de investimentos para seus locais de moradia. Em suas falas havia a ideia de quebra dos estereótipos negativos sobre a favela presente no imaginário coletivo da cidade $^{8}$. A veiculação na grande imprensa da favela pacificada pelo Estado como um território da paz, livre da violência, atuou no sentido de promover a imagem de jovens autoempreendedores, distanciados do "crime", simbolizando a distinção entre o bem e o mal. Nas falas seguintes, os depoentes frisam essa mudança:

"A mesma mídia que dizia que você era um favelado, que você era um criminoso, hoje diz que você é um jovem pleno de direitos e que você hoje pode ser modelo, "a modelo do alemão", "o fotógrafo do alemão."

“Todo mundo tá vendo que o que está na moda é trabalho, curso, aprendizado, tudo isso daí que está acontecendo agora com a gente. Mudança né? A pessoa melhorar, mudar para melhor. Começou agora, depois das implantações, mas não pela UPP, mas mais pelo trabalho social que está chegando devagarzinho."

\footnotetext{
${ }^{8}$ Esses estereótipos podiam ser vislumbrados de vários modos, como o "apelido" pelo qual o conjunto de favelas do Alemão era conhecido - "Faixa de Gaza do Rio de Janeiro", em referência aos conflitos entre palestinos e israelenses no Oriente Médio. Contribuíram para esta representação os constantes tiroteios entre facções rivais e entre estes e a polícia; os elevados números de assaltos nos bairros vizinhos, atribuídos a ações comandandas por traficantes do Complexo do Alemão; e o brutal assassinato do jornalista Tim Lopes, da Rede Globo de Televisão, em 2002.
} 
Isso significa dizer que, apesar da UPP, enquanto agência policial ser um polo repulsivo entre os jovens, muitos deles valorizaram as mudanças que ocorreram imediatamente após a chamada "pacificação". A principal delas decorreu da alteração percebida na imagem sobre seus locais de moradia, permitindo que mais pessoas "de fora" circulassem pela favela, sem se confrontar com homens armados e o perigo dos constantes tiroteios que interrompiam a rotina dos moradores. É possível dizer que, para alguns jovens do Complexo do Alemão, o "tráfico" havia saído de moda, na medida em que o retraimento das atividades costumeiras de venda e consumo de drogas ilícitas, ao restringir a presença das armas acabou por abalar o prestígio conferido aos homens que as ostentavam.

Nas entrevistas, ouvimos ainda colocações sobre o impacto dessa nova configuração no mercado afetivo-sexual. Alguns rapazes passaram a vislumbrar uma posição mais favorável nas relações de namoro e paquera, a partir de uma certa desvalorização da hipermasculinidade, marca diacrítica exigida dos integrantes das quadrilhas. Esse modelo de masculinidade precisa dar provas constantes de coragem, inclusive correr riscos sérios, como a morte em nome da moral ou da "consideração" entre os pares ( Cecchetto, 2004).

Num dos encontros, em que apenas os jovens homens estavam presentes, a preferência das moças para com os homens que exibiam o poder através da violência, (incluindo, eventualmente os policiais das unidades), foi um tópico mencionado em tom de acusação. Mencionou-se o prestígio que seus pares "envolvidos" no crime-negócio tinham no mercado afetivo-sexual ${ }^{9}$. Entretanto, cabe notar que, nos encontros em que

\footnotetext{
${ }^{9}$ Esse não é somente o caso dos homens armados que integram os chamados "comandos" no Rio de Janeiro. Como alguns estudos já mostraram, há uma percepção de que os homens envolvidos com bandos ou quadrilhas são mais cobiçados como parceiros sexuais pelas mulheres, servindo de referência para outros rapazes, embora muitos morram para provar que são homens de verdade (Barker, 2008).
} 
ambos os gêneros estavam presentes, o assunto não foi abordado, nem mesmo pelas meninas. Observou-se, de outro modo, que as moças eram bem mais críticas que seus colegas homens quanto à violência, viesse ela da polícia ou do tráfico. Já os jovens citaram enfaticamente a truculência policial.

Ouvimos opiniões típicas e previsíveis sobre o que significava ser tratado, rotineiramente, como um elemento suspeito. As constantes "duras" que recebem dos policiais durante as operações na favela são narradas com certo humor, mas o medo impregna a maioria dos depoimentos de ambos os sexos diante dos abusos do poder de polícia que eles denominam como "esculachos". Para os homens, essa situação é particularmente crítica, porque é o grupo que mais deve se preocupar com as ameaças de violência não só da polícia, mas também a dos bandos armados. Uma simples acusação de traição, sem provas, é o suficiente para considerar alguém como um "inimigo" a ser punido, muitas vezes com a morte, pelos códigos ditados pelos traficantes.

Por isso, nas conversas que tivemos com os jovens, os binômios desconfiança/confiança, lealdade/traição eram frequentes, exprimindo as tensões oriundas do convívio com a lógica faccionalista que predomina nos territórios conflagrados. Não se trata de falar de uma "cultura do crime", mas compreender as articulações entre o crime-negócio e a homossociabilidade que parecem irrigar as relações dos que ali transitam e interagem. Os acordos tácitos envolvem benefícios e proteção que são ofertados pelos "donos" aos "amigos", gerando sobre alguns uma expectativa positiva de estar em um circuito considerado próspero, lúdico e próximo. São inúmeros os rituais de interação em atividades recreativas, com entrada franqueada também aos familiares e "amigos dos amigos". Nessa atmosfera, as regras relacionadas tanto a distribuição de bens materiais quanto simbólicos, incluindo lealdade, proteção e 
confiança, aparecem cada vez mais "misturadas", tornando seus limites imprecisos na economia simbólica da reciprocidade. Por isso, muitos moradores e principalmente os homens jovens recebem a acusação de serem "envolvidos" pela polícia, pelos próprios vizinhos e pela sociedade mais ampla. Tema que precisa ser melhor explorado em futuras pesquisas etnográficas nas favelas cariocas.

\section{O futuro, hoje - os jovens e os projetos em 2015}

Desde o início das atividades, os jovens de ambos os sexos relatavam um certo desconforto por se dedicarem a um curso voltado para a construção civil. Esse desconforto era sentido também por seus familiares que desconfiavam das promessas feitas pelos gestores quanto à empregabilidade. A maior parte dos rapazes já havia trabalhado como "ajudante de pedreiro", atividade que demandava um alto esforço físico e baixo retorno financeiro. No entanto, a promessa de empregabilidade e o auxílio recebido durante o período em que assistiram às aulas atuaram como fatores decisivos para seu comparecimento às atividades, incluindo as moças que estavam também à procura de emprego e renda.

Em 2015, em novo contato com os jovens, soubemos que, ao final do curso, poucos foram encaminhados ao mercado de trabalho, porém em postos informais e/ou temporários. Mas o sonho da carteira assinada não se concretizou para nenhum deles. A frustração foi ainda maior entre as mulheres, pelo fato de terem sido estimuladas a investir em um ramo em que a participação feminina ainda é fortemente vetada. Mesmo os dois rapazes que conseguiram se manter por um tempo maior no posto de trabalho como pedreiros afirmavam que, apesar da melhor qualificação por conta das técnicas 
aprendidas, persistia a desvalorização dessa categoria profissional no mercado de trabalho.

No entanto, ainda que a meta de contribuir para a ampliação das oportunidades de emprego não tenha sido plenamente contemplada, muitos passaram a vislumbrar a possibilidade de trabalhar por conta própria. Um desdobramento dessa iniciativa foi a ideia de criar uma pequena empresa gerenciada por eles mesmos para fornecer serviços de construção civil na favela.

Outro legado enfaticamente valorizado pelo grupo foi o aprofundamento do convívio entre os pares e o reforço dos laços de vizinhança. Não é difícil imaginar o quanto o fortalecimento da confiança entre os pares é importante para driblar a sensação de insegurança em uma localidade em que as rotinas são constantemente alteradas por confrontos violentos ${ }^{10}$.

Em 2015, no Complexo do Alemão esse quadro se agravou ${ }^{11}$ com o aumento de operações policiais violentas na localidade e execuções de moradores atribuídas a policiais durante os confrontos com os criminosos, acentuando as críticas já feitas à política de pacificação das UPP desde sua implantação nas favelas do Rio de Janeiro. Nesse processo, a hostilidade nas interações entre moradores e policiais se intensificou, realimentada pelas intimidações exercidas pelos bandos armados na luta pelo poder e controle territorial, configurando mais uma vez a "vida sob cerco", entre a violência da polícia e a do tráfico (Machado da Silva, 2008).

\footnotetext{
${ }^{10}$ Porém, apesar de terem que lidar constantemente com a imprevisibilidade cotidiana que afeta sua segurança ontológica, eles utilizam a expressão "tranquilo" para descrever situações e contextos reconhecidamente conturbados por "guerras" entre facções e/ou das incursões policiais.

${ }^{11}$ Em 02/04/2015 o globo online publicou a matéria "Moradores do Alemão convivem com tiroteios há 90 dias seguidos". Disponível em: < http:/g1.globo.com/rio-de-janeiro/noticia/2015/04/moradores-do-alemao-convivemcom-tiroteios-ha-90-dias.html>. Acesso em: 11/07/2015.
} 
Se inicialmente os jovens apropriaram-se das oportunidades abertas pelas iniciativas e investimentos que chegavam à favela com o advento das UPP, atualmente a escassez das iniciativas, aliada ao aumento da repressão violenta da polícia, reforça a percepção entre eles da dificuldade de escapar do destino já traçado da "vulnerabilidade".

Além disso, eles tiveram, desde o início, como já mencionamos, a noção da precariedade e da provisoriedade das políticas públicas a eles dirigidas. Não foram poucas as falas que ponderavam sobre a dificuldade de falar sobre UPP em virtude de seu caráter temporário. O fato de se sentirem como os "elementos suspeitos" e não os sujeitos da proteção pela polícia acentuava ainda mais a desconfiança com relação às iniciativas dirigidas a seus locais de moradia. Um rapaz por nós entrevistado em 2012, comentando uma conversa com o então secretário de Segurança Pública do governo, relatou:

“Eu perguntei ao Beltrame [secretário de Segurança Pública] se ele tinha como me garantir que a UPP fosse eterna e ele disse que não. A UPP é uma política de governo, não é uma política de Estado. Então é difícil falar sobre a UPP porque eu não sei se essa segurança é para mim na verdade, não é para me proteger. Eu não vejo isso nas ações das UPP (...) A formação deles [policiais] é que todo mundo aqui [na favela] é um suspeito. Eu sou um suspeito."

Num contexto em que a confiança nas instituições estatais e nas políticas públicas se mostra cada vez mais distante, o lema "nós por nós mesmos" vem sendo recorrentemente acionado pelos moradores. No momento em que terminamos a escrita 
deste trabalho, a conjuntura atual de crise econômica no país tem se refletido de maneira perversa sobre a juventude moradora dessas localidades. Em razão disto, o título deste artigo Quando o projeto era moda: projetos sociais, juventudes e "pacificação" ajuda a compreender as resistências e desconfianças dos jovens para com o que se propunha ser uma inovação na segurança pública e nas oportunidades de ascensão social.

O engajamento nas atividades promovidas pelos chamados projetos sociais, que muitas vezes constituem a forma como as políticas públicas de juventude se materializam nos territórios da pobreza também passa por esse cálculo entre expectativas versus reais possibilidades de mudança em suas vidas. Uma das limitações desse discurso e dessa atuação dos projetos e de seus organizadores parece ser justamente a precariedade que perpassa toda essa dinâmica. Por isso, a ênfase dada ao esforço individual para superar as dificuldades, como pontuam os discursos dos gestores, também é vista com desconfiança.

Não se trata de ignorar as ações e as oportunidades abertas por iniciativas dos projetos sociais. De fato, a trajetória nesse circuito proporciona aos jovens um aporte maior de recursos, principalmente simbólicos, reconfigurando seu capital social a partir da inserção em novas redes de sociabilidade, de maior prestígio social e poder econômico, conforme é possível observar no depoimento de um entrevistado:

"Eu lembro do dia exato quando eu fui convidado no meu primeiro projeto, quando me inseri nesse mundo social. Eu estava na [nome do lugar], sentado, conversando com o $\mathrm{X}$ e o $\mathrm{Y}$ e eles receberam um telefonema e me convidaram para participar. Eu conheci um novo mundo. Comecei a entender uma outra realidade. Meu pontapé inicial 
foi em 2007. Eu participei em diversos projetos que não tenho nem como elencar agora. Eu me considero um jovem privilegiado por isso..."

No entanto, é preciso estar atento ao fato de que enquanto as políticas voltadas para a juventude, incluindo as de segurança pública, forem apenas moda, não será possível a mudança perene que de fato assegure condições de mobilidade social, ampliando o horizonte de expectativas de inclusão social. Políticas de estímulo à manutenção dos jovens pobres na escola são absolutamente cruciais, assim como políticas de segurança pública mais sensíveis aos segmentos juvenis.

Quanto ao outro eixo de questões, ligado ao contexto de instalação das UPP, é importante observar que o processo de "pacificação" é algo muito mais complexo que uma questão de instalação, formalizações e financiamentos de postos de policiamento. Segundo alguns estudiosos, no decorrer de cinco anos de UPP, um dos maiores desafios para consolidar uma política de proximidade é garantir uma oferta igualitária, legal e legítima de serviços de policiamento público em comunidades populares (ver especialmente Muniz e Mello 2015).

Para os nossos entrevistados, os sentidos dados à "pacificação", ou, mais especificamente, à polícia estão ligados às ocupações militarizadas das favelas como se territórios "inimigos" fossem. Com efeito, é exatamente a alegada repressão ao 'tráfico de drogas" o motor principal da "guerra contra o crime" que mobiliza a maior parte das atividades policiais, não só no Rio de Janeiro, mas em outras partes do Brasil e do mundo (ver sobre isso Zaluar, 2014; e Karam, 2015) ${ }^{12}$.

\footnotetext{
12 Os alvos dessa guerra são os pequenos vendedores de drogas no varejo, demonizados como "traficantes". Geralmente são homens jovens e negros com baixa escolaridade, cujas dificuldades cotidianas favorecem a busca de alternativas de sobrevivência econômica, o que os leva, porém, à morte precoce em incontáveis combates com as gangues rivais e com a polícia.
}

RRASILIANA- Journal for Brazilian Studies. Vol. 4, n.2 (2016). ISSN 2245-4373. 
Repensar as formas de atuação policial em territórios tradicionalmente conflagrados por vários tipos de "guerra" não é tarefa fácil; mais difícil ainda é remodelar as formas de agir da polícia sobretudo com os homens jovens. Esta é uma tarefa complexa e deve ser tomada como prioridade pelas autoridades e por toda a sociedade e requer um trabalho contínuo nos níveis individual, comunitário e social.

Por fim, para que seja possível mudar o quadro de elevadas taxas de homicídio que atingem os jovens envolvidos ou não com a criminalidade é preciso desenvolver políticas de segurança que incorporem também reflexões sobre paradigmas de gênero. O ponto-chave é que os chamados papéis de gênero que orientam comportamentos e práticas de homens e mulheres podem ser construídos e reconstruídos e devem ser criticamente questionados em suas versões mais rígidas e hegemônicas.

\section{Referências}

Almeida, Maria Isabel Mendes de. 2008. 'Juventude E Empreendedorismo: Uma Abordagem Das Novas "Subjetividades Executivas"'. Desigualdade E Diversidade 3. https://www.espm.br/ConhecaAESPM/CAEPM/nucleodeestudosdajuventude/Documen ts/Banco\%20de\%20Dados\%20Jovens/4.\%20JOVENS\%20E\%20TRABALHO/4.3.\%20joven s\%20empreendedorismo.pdf.

Arce, Manuel Valenzuela. 1999. Vida de barro duro. Cultura popular juvenil e grafitti. Rio de Janeiro, EdUFRJ.

Barker, Gary T. 2008. Homens Na Linha De Fogo: Juventude, Masculinidade E Exclusão Social. Rio de Janeiro: 7Letras.

Bourdieu, Pierre, and Loïc J. D Wacquant. 2008. Una Invitación A La Sociología Reflexiva. Buenos Aires: Siglo Veintiuno Editores Argentina. 
1983. "A juventude é apenas uma palavra". In: Questões de sociologia, Rio de Janeiro, Marco Zero.

Cano, Ignacio, Doriam Borges, and Eduardo Ribeiro. Os Donos Do Morro: uma avaliação exploratória do impacto das unidades de polícia pacificadora (UPPs) no Rio de Janeiro. Rio de Janeiro: Fórum Brasileiro de Segurança Pública - LAV-UERJ, 2012

Cardoso, Adalberto. 2013. 'Juventude, Trabalho e Desenvolvimento: Elementos Para Uma Agenda De Investigação'. Caderno CRH 26 (68): 293-314. doi:10.1590/s010349792013000200006.

Cecchetto, Fátima. 2004. Violência e estilos de masculinidade. Rio de Janeiro. Fundação Getúlio Vargas Ed.

Cecchetto, Fátima, and Patrícia Farias. 2009. 'Tu Mora Onde?" Território E Produção De Subjetividade No Espaço Urbano Carioca'. In Cidade: Olhares E Trajetórias, 1st ed. Rio de Janeiro: Garamond.

Corrêa, Juliana Silva. 2013. 'As Representações De Jovens Moradores Do Complexo Do Alemão No Rio De Janeiro Sobre A Implantação Das Unidades De Polícia Pacificadora UPP'. Dissertação, Escola Nacional de Saúde Pública -ENSP, Fundação Oswaldo Cruz.

Dubet, François. 1987. La galère - jeunes em survie. Paris, Fayard.

Farias, Patrícia. 2003. Pegando uma cor na praia: relações raciais e classificação de cor na cidade do Rio de Janeiro. Rio de Janeiro, Prefeitura da Cidade/Secretaria das Culturas.

Karam, Maria Lúcia; 2015. Legalização das drogas São Paulo, Estúdio Editores. Coleção Para Entender Direito.

Landim, Leilah. 1993. 'A Invenção Das Ongs: Do Serviço Invisível A Profissão Sem Nome'. Doutorado, Museu Nacional. Universidade Federal do Rio de Janeiro.

Lipovestky, Gilles. 2009. O império do efêmero - a moda e seu destino nas sociedades modernas. São Paulo, Cia. Das Letras. 
Machado da Silva, Luiz Antônio. A.(org.). Vida sob cerco: violência e rotina nas favelas do Rio de Janeiro. Nova Fronteira, 2008.

. 2010. 'Afinal, Qual É A Das Upps?'. Observatório Das Metrópoles. http://www.observatoriodasmetropoles.ufrj.br/artigo_machado_UPPs.pdf.

Misse, Michel. 2011a. 'Crime Organizado E Crime Comum No Rio De Janeiro: Diferenças E Afinidades'. Rev. Sociol. Polit. 19 (40): 13-25. doi:10.1590/s010444782011000300003.

Misse, Michel. 2011. 'A Categoria "Bandido" Como Identidade Para O Extermínio: Algumas Notas Sobre Sujeição Criminal A Partir Do Caso Do Rio De Janeiro'. In Violência E Dilemas Civilizatórios: As Práticas De Punição E Extermínio, 1st ed. Campinas: Pontes Editores.

Monteiro, Rodrigo de Araújo. 2009. 'Prevenção Da Violência: O Caso De Projetos Sócio Esportivos Nos Subúrbios Cariocas'. Doutorado, Universidade do Estado do Rio de Janeiro.

Muniz, Jacqueline De Oliveira, and Kátia Sento Sé Mello. 2015. 'Nem Tão Perto, Nem Tão Longe: O Dilema Da Construção Da Autoridade Policial Nas Upps'. Civitas - Revista De Ciências Sociais 15 (1): 44. doi:10.15448/1984-7289.2015.1.19939.

Novaes, Regina. 2006. 'Os Jovens De Hoje: Contextos, Diferenças E Trajetórias'. In Culturas Jovens: Novos Mapas Do Afeto, 1st ed. Rio de Janeiro: Zahar.

Pais, José Machado. 1990. A construção sociológica da juventude- alguns contributos. Análise Social, v.XXV (105-106), p.139-165.

Waiselfisz, Julio Jacobo. 2015. Mapa Da Violência 2015: Mortes Matadas Por Armas De Fogo. Brasília: FLACSO. http://www.mapadaviolencia.org.br/pdf2015/mapaViolencia2015.pdf.

Zaluar, Alba. 2004. Integração Perversa. Rio de Janeiro: Editora FGV. . 2014. 'Sociability In Crime. Culture, Form Of Life Or Ethos?'. Vibrant, Virtual Braz. Anthr. 11 (2): 12-46. doi:10.1590/s1809-43412014000200001. 